\title{
Células dendríticas especializadas en presentación de antígenos exógenos a linfocitos $T$ citotóxicos
}

\author{
Specialized dendritic cells in cross-presentation of exogenous \\ antigens to cytotoxic T lymphocytes
}

\author{
C. Alfaro ${ }^{1}$, C. Oñate ${ }^{1}$, A. Rodríguez ${ }^{1}$, J.L. Pérez-Gracia ${ }^{2}$, M. Fernández de Sanmamed ${ }^{1,2}$, \\ I. Melero ${ }^{1,2}$
}

\section{RESUMEN}

Las células dendríticas son células de origen hematopoiético, que expresan constitutivamente moléculas presentadoras de antígeno MHC de clase I y II, y son funcionalmente las inductoras más potentes de la activación y proliferación de linfocitos T a los que presentan antígenos. Los linfocitos T CD8+ proliferan y adquieren capacidad citotóxica cuando reconocen su antígeno específico presentado en la superficie de una o varias células dendríticas con las que interactúan. Sin embargo, solamente algunas subpoblaciones de células dendríticas pueden presentar antígenos internalizados desde el exterior celular a través de procesos de pinocitosis y fagocitosis a precursores de linfocitos T citotóxicos. Esta función se denomina presentación cruzada o presentación subrogada (en inglés, crosspresentation) y requiere mecanismos de translocación de los antígenos que se encuentran internalizados en fagosomas al citosol para su procesamiento. Se ha establecido que la diferenciación de subpoblaciones de células dendríticas con capacidad de efectuar este tipo de presentación cruzada a linfocitos T CD8+ son dependientes del factor de crecimiento FLT-3L y del factor de transcripción BATF3. Presentan peculiaridades tanto funcionales como de marcadores de membrana que nos permiten identificarlas. En ratones se distinguen por la expresión de CD8 $\alpha$ y en humanos por la de CD141 (BDCA3). Esta población en ambas especies es capaz de internalizar selectivamente restos de células necróticas mediante su receptor CLEC9A que se une a actina polimerizada extracelular. Disponen del receptor de quimioquinas XCR1 que asegura su encuentro con linfocitos T CD8+. La vacunación terapéutica con antígenos tumorales utilizando células dendríticas es una estrategia en desarrollo para el tratamiento del cáncer. La utilización de subpoblaciones de células dendríticas con mayor capacidad de realizar presentación cruzada o subrogada remeda los mecanismos naturales de inmunización para inducir linfocitos T citotóxicos. La dianización in vivo de antígenos a estas subpoblaciones celulares mediante anticuerpos monoclonales anti-DEC-205 o anti-CLEC9A consigue respuestas inmunitarias muy intensas y se están probando en ensayos clínicos frente a viriasis crónicas y enfermedades malignas.

Palabras clave. Células dendríticas. Presentación cruzada/ Presentación subrogada. CD8-alfa. BDCA-3. CLEC9A.

\begin{abstract}
Dendritic cells (DC) are cells of hematopoietic origin, which constitutively express MHC class I and II, and are functionally the most potent inducers of T-lymphocyte activation and proliferation. CD8+ T lymphocytes proliferate and acquire cytotoxic functions upon recognition of their cognate antigen on the surface of one or various dendritic cells with which they interact. However, only some DC subsets are able to present antigen to cytotoxic $T$ cell precursors as taken up from extracellular sources. This function is termed cross-presentation (in Spanish, presentación cruzada or presentación subrogada) and requires shuttle mechanisms from phagosomes to the cytosol for antigen processing. It has been demonstrated that the differentiation of DC with these capabilities is dependent on FLT-3L and the transcription factor BATF3. They express peculiar functions and differentiation markers. These cells are distinguished in mice by surface CD8 $\alpha$ features, while CD141 (BDCA-3) marks these cells in the human. These subpopulations are capable of selective internalization of necrotic cell debris by means of their CLEC9A lectin which is a receptor for extracellular polymerized actin. Expression of the chemokine receptor XCR1 favours contact with CD8+ T cells. Therapeutic vaccination with tumour antigens using DC is a strategy under development for the treatment of cancer. The use of DC subsets with more prominent capabilities for cross-presentation would mimic the natural mechanisms of immunization to induce cytolitic $\mathrm{T}$ lymphocytes. In vivo targeting of antigens with monoclonal antibodies against DEC-205 or CLEC9A attains very robust immune responses and is a strategy undergoing clinical trials for chronic viral diseases and malignancies.
\end{abstract}

Key words. Dendritic cells. Cross-presentation. CD8-alpha. BDCA-3. CLEC9A.

\section{An. Sist. Sanit. Navar. 2013; 36 (3): 519-537}

1. Área de Terapia Génica y Hepatología. Centro de Investigación Médica Aplicada. Universidad de Navarra. Pamplona.

2. Departamento de Oncología Médica. Clínica Universidad de Navarra. Universidad de Navarra. Pamplona.

Recepción: 19 de junio de 2013

Aceptación provisional: 3 de septiembre de 2013

Aceptación definitiva: 11 de septiembre de 2013

\section{Correspondencia:}

Ignacio Melero

Clínica Universidad de Navarra (CUN)

Centro de Investigación Médica Aplicada (CIMA)

Avda. Pio XII, 55

31008 Pamplona

imelero@unav.es 


\section{CÉLULAS DENDRÍTICAS}

Las células dendríticas fueron observadas por primera vez en la piel por el histólogo alemán Paul Langerhans a finales del siglo XIX. Sin embargo la función inmunológica de las células de Langerhans de la piel pasó inadvertida durante al menos siete décadas. El término célula dendrítica (CD) no fue utilizado hasta 1973, por R. M. Steinman y ZA. Cohn, y deriva del hecho de que estas células tienen prolongaciones que remedan la morfología de las dendritas neuronales. Los estudios de Steinman definieron las CD, observando aquellas que ahora clasificamos en el subgrupo de CD mieloides o convencionales. Sus estudios postularon las CD como una población celular minoritaria de órganos linfoides caracterizada morfológicamente por múltiples prolongaciones en forma de ramas (dendritas) y que era capaz de activar linfocitos $\mathrm{T}$ sin experiencia antigénica previa $^{1-3}$. Por estos descubrimientos le fue otorgado el premio Nobel de medicina en 2011, galardón que premiaba una larga trayectoria de descubrimientos dedicada a esclarecer paulatinamente la relevancia de estas células en la fisiología del sistema inmunitario $^{4,5}$. El profesor Steinman no llegó a conocer la concesión de este galardón ya que falleció dos días antes de que le fuera comunicada la noticia (Fundación Nobel, http://www.nobelprize.org/).

Las CD, según Steinman, son los "centinelas naturales del sistema inmune", siendo las encargadas de decidir si se induce o si no se pone en marcha una respuesta inmunitaria adaptativa ante la invasión de gérmenes patógenos ${ }^{6}$. Las CD derivan de precursores hematopoyéticos y son principalmente de linaje mieloide, aunque se ha puesto de manifiesto su plasticidad ontogénica $^{7}$. A menudo, aunque no siempre, presentan una morfología con prolongaciones celulares retráctiles que les permiten aumentar la superficie para establecer contactos intercelulares ${ }^{8}$.

$\mathrm{Al}$ ser las principales células profesionales presentadoras de antígeno, son importantes tanto en la estimulación/activación como en la regulación de la inten- sidad de la respuesta de linfocitos $\mathrm{T}$ y linfocitos $\mathrm{B}^{9}$. Se postula que, en ausencia de estímulos microbianos o inflamatorios, las CD permanecen en estado de reposo (llamado inmaduro), en el cual su capacidad de activación de linfocitos $\mathrm{T}$ se encuentra activamente reprimida ${ }^{10}$. La exposición de las $\mathrm{CD}$ a agentes infecciosos provoca varios cambios funcionales y de expresión génica, los cuales en forma coordinada, mejoran notoriamente su capacidad para interactuar con los linfocitos $\mathrm{T}$ a los que presentan antígeno y promover tanto su proliferación como su diferenciación funcional $^{11}$. El término maduración de células dendríticas se utiliza para referirnos a esta activación funcional, que se plasma en la puesta en marcha de un programa de expresión génica y en la modificación de su patrón de migración en respuesta a estímulos quimiotácticos, merced a cambios en la expresión de receptores de quimioquinas ${ }^{12}$.

En el estado inmaduro, las CD están especializadas en internalizar material potencialmente antigénico tanto exógeno al organismo como endógeno (procedente principalmente de detritus celulares) y para ello poseen una maquinaria de endocitosis muy eficiente ${ }^{13}$. La captación de antígenos está facilitada por receptores endocíticos de superficie ${ }^{14}$, tales como: receptores para el Fc de las inmunoglobulinas (CD32), receptores de complemento, integrinas, receptores tipo lectina C (CD209, CD205, BDCA, langerina, receptores de manosa) y receptores tipo scavenger (LOX-1, CD91, CD36).

En el estado inmaduro, las CD muestran escasa densidad en su superficie de moléculas presentadoras de antígeno del complejo mayor de histocompatibilidad de clase I y II (MCH-I y MHC-II) y de moléculas co-estimuladoras (CD40, CD80 y CD86). Por el contrario su superficie es rica en receptores implicados en captación de antígeno por endocitosis, fagocitosis y, sobre todo, macropinocitosis, tales como los receptores para el Fc de inmunoglobulina, de manosa y para factores activados del complemento.

En esta situación de inmadurez (o falta de activación), las $\mathrm{CD}$ son capaces de in- 
ducir y mantener la tolerancia frente a autoantígenos en tejidos periféricos, ya que continuamente presentan los antígenos propios a los linfocitos $\mathrm{T}$, de manera que en los linfocitos específicos de autoantígenos se induce apoptosis o anergia funcional ${ }^{15}$. Por tanto, la presentación de autoantígenos por células dendríticas inmaduras en condiciones de normalidad elimina del repertorio de reconocimiento a aquellos clones de linfocitos $\mathrm{T}$ potencialmente autoreactivos ${ }^{10}$.

En el tejido inflamado aumenta considerablemente la capacidad de macropinocitosis de las CD y la expresión de receptores que permiten la captación de antígeno. Asimismo parte de los monocitos que penetran el tejido de novo para formar el infiltrado inflamatorio, se diferencian in situ en células dendríticas ${ }^{16}$. También se activa la biosíntesis de moléculas de MHC-I y II, que forman complejos con eficiencia tanto con péptidos originados en la propia célula dendrítica como con polipéptidos externos que han captado en el tejido inflamado. Cuando son estimuladas por citoquinas proinflamatorias (TNF- $\alpha$, IL-1 $\beta$, IL-6, INF- $\alpha$ ) o por el ligando de CD40 (CD40L), expresado sobre linfocitos $\mathrm{T}$ cooperadores (T helper), las CD se activan diferenciándose a CD maduras (CDm). En este estado expresan en la superficie celular CD80 y CD86 con mayor densidad ${ }^{16}$. Además, las CDm también adquieren la expresión de CD83 en su superficie. Estas glicoproteínas de membrana confieren capacidad para estimular aquellos linfocitos $\mathrm{T}$ que reconocen sobre ellas su antígeno específico.

Otra característica de las CDm es su capacidad regulada de secretar IL-12 ${ }^{17}$ y de otras citoquinas activadoras de células $\mathrm{T}$ tales como IL-15 ${ }^{18,19}$, IFN- $\alpha^{20,21}$ o IL-2 ${ }^{22}$. La producción de IL-12 está implicada en la inducción de respuestas de linfocitos $\mathrm{T}$ helper productores de IFN- $\gamma$ (linfocitos Th1) y en la activación de linfocitos $\mathrm{T}$ citotóxicos (CTL) efectores ${ }^{23}$.

Al madurar, las CD modifican el patrón de expresión de receptores de quimioquinas de forma que se pierde la expresión de CCR1 y CCR5 y así pueden salir del territorio inflamado ${ }^{24}$. La adquisición de la ex- presión de CCR7 permite que sean atraídas a vasos linfáticos aferentes para comenzar su recorrido rumbo hacia órganos linfoides secundarios $^{25-27}$.

Como resultado de su maduración, las CD experimentan un incremento de la estabilidad en la membrana plasmática de sus complejos MHC/péptido y pierden la capacidad de captación y procesamiento de nuevos antígenos. Se piensa que estos cambios disminuyen dicho procesamiento durante la migración a los órganos linfoides secundarios (ganglios linfáticos, bazo, amígdalas o tejido linfoide asociado a mucosas).

Cuando llegan a dichos órganos, las células dendríticas maduras se emplazan en las zonas interfoliculares del paracórtex ricas en células $\mathrm{T}$, donde realizan su función de presentar péptidos antigénicos a aquellas células T específicas que allí se encuentren $^{24}$. Sin el guiado de las quimioquinas, el encuentro entre el linfocito específico y la célula presentadora sería un fenómeno muy improbable. En una serie de encuentros concertados por quimioquinas y en los que intervienen moléculas de adhesión los linfocitos $\mathrm{T}$ rastrean aquellas CD sobre la que su receptor clonotípico de antígeno (TCR) efectúa el reconocimiento específico. El sentido fisiológico de estos fenómenos celulares es que de esta manera se inicie y sostenga la respuesta inmune contra un agente agresor cuyos antígenos han sido captados en un foco inflamatorio ${ }^{24}$. Esta respuesta implica la multiplicación de los linfocitos $\mathrm{T}$ específicos para el antígeno (expansión clonal) y la adquisición de funciones efectoras, proinflamatorias, citolíticas o de cooperación para respuestas de anticuerpos.

Existen dos clases de estímulos que inducen la transformación de las CD en formas inmunológicamente maduras $\mathrm{y}$, por consiguiente, capaces de activar linfocitos T. Uno de ellos consiste en el reconocimiento de patrones moleculares asociados a gérmenes ${ }^{28}$. Carles Janeway fue el primer inmunólogo en postular que la detección de un antígeno en el contexto de señales moleculares de infección eran críticos para la inducción de respuestas inmunitarias. 
El otro tipo de estímulos depende de la exposición de las $\mathrm{CD}$ a señales endógenas peligrosas, como las sustancias liberadas por células dañadas ${ }^{29-31}$. La importancia del daño celular fue postulada por Polly Matzinger como un factor crítico en la iniciación de la inmunidad ${ }^{29}$. Cada vez parece más claro que sustancias endógenas que denotan daño (alarminas) y patrones moleculares de gérmenes (PAMPs) actúan de modo coordinado en la activación de $\mathrm{CD}^{32}$. Existen diferentes tipos de sistemas de receptores que las $C D$ utilizan para reconocer patrones moleculares asociados a gérmenes o a daño celular (derivados de biomoléculas de virus, bacterias, sustancias producidas por células dañadas, etc ${ }^{23}$. El receptor toll-like receptor-4 (TLR-4) está implicado tanto en la detección de endotoxina bacteriana como en la de señales moleculares de estréss, tales como la presencia extracelular de la proteína nuclear HMGB1 $^{33}$.

Se ha demostrado que según la naturaleza del estímulo madurativo, las CDm pueden modificar sus funciones, adecuando el tipo de inmunidad que despiertan a la naturaleza del agente nocivo que la desencadena. Se ponen en marcha así respuestas linfocitarias con funciones efectoras diversas y especializadas ${ }^{17,34,35}$. Asimismo, hay distintas líneas experimentales que sugieren que aunque las $\mathrm{CD}$ experimentan cambios madurativos en respuesta a citoquinas proinflamatorias, en ausencia de patrones moleculares de gérmenes o daño tisular las señales son insuficientes para capacitarlas de cara a la activación de linfocitos T efectores $^{29}$.

Se han efectuado numerosos experimentos utilizando CD diferenciadas en cultivos a partir de monocitos de sangre periférica en humanos o de precursores de médula ósea de ratones en presencia de GM-CSF y otros factores de crecimiento $^{36,37}$. Los monocitos CD14+ o suspensiones celulares de médula ósea son cultivados in vitro en presencia del factor estimulante de colonias de granulocitos y macrófagos (GM-CSF) e IL- $4^{38}$, IFN- $\alpha^{39}$ o IL- $15^{40}$, logrando así su transformación en potentes células presentadoras $^{15,23,34,41}$.
Existe una subpoblación de CD que circula en la sangre y está presente en órganos linfáticos denominada CD plasmocitoide. Su rasgo funcional más llamativo es que producen grandes cantidades de las proteínas antivirales INF- $\alpha$ e IFN- $\beta$ en respuesta a la presencia de virus ${ }^{42-44}$. Las CD plasmocitoides detectan la presencia de RNA de características virales en sus endosomas a través del receptor TLR- $7^{45-47}$. El papel de estas células en presentación antigénica ha sido controvertido, pero en artículos recientes se ha demostrado su capacidad de presentar antígeno tanto a linfocitos T CD4 y CD8 en las condiciones $\operatorname{adecuadas}^{48,49}$.

\section{EL FENÓMENO DE LA PRESENTACIÓN CRUZADA O SUBROGADA A LINFOCITOS T CITOTÓXICOS}

Los fenómenos bioquímicos de proteolisis y ensamblaje en moléculas presentadoras de antígeno se conocen como procesamiento antigénico e implican la degradación de los antígenos proteicos a péptidos más cortos. Estos péptidos son adsorbidos en moléculas de presentación antigénica del complejo principal de histocompatibilidad y así son dispuestos para su presentación en la membrana plasmáti$\mathrm{ca}^{50}$. La presentación antigénica es el conjunto de fenómenos y mecanismos que hacen accesible en la membrana de la célula presentadora de esos péptidos asociados a moléculas MHC para su reconocimiento por parte de los linfocitos $\mathrm{T}^{50}$.

Las células implicadas en el proceso de presentación de antígeno son, por un lado, las células presentadoras que muestran en su membrana los complejos MHC-antígeno $\mathrm{y}$, por otro, los linfocitos $\mathrm{T}$ que aportan sus receptores específicos de antígeno denominados TCRs, que son capaces de reconocer el péptido antigénico en asociación a una molécula presentadora propia ${ }^{51}$. La activación de la célula T no sólo exige que exista un reconocimiento molecular entre el complejo MHC-antígeno y el TCR, sino que también requiere un conjunto adicional de interacciones entre las proteínas de 
membrana de ambas células y de factores solubles paracrinos (citoquinas).

Dependiendo del tipo de antígeno y de la ruta de procesamiento los antígenos pueden presentarse asociados a moléculas de clase I (MHC-I) o moléculas de clase II (MHC-II), lo que permitirá el reconocimiento antigénico por subpoblaciones diferentes de linfocitos ${ }^{51}$. Todas las células nucleadas expresan moléculas de MHC de clase I en su membrana, pero solo las células presentadoras de antígeno (APC) especializadas presentan moléculas de MHC de clase II y, en condiciones normales, incluyen los macrófagos, las CD y los linfocitos $\mathrm{B}$ activados. A estas células que expresan MHC de clase II las denominamos células profesionales presentadoras de antígeno; si bien en sentido estricto solamente las células dendríticas son capaces de desempeñar estas funciones con la eficiencia necesaria para iniciar una respuesta inmunitaria a partir de linfocitos sin experiencia antigénica previa.

Las moléculas MHC de clase I, en una situación normal, se unen a péptidos derivados de proteínas propias (traducidas en la propia célula) que son degradadas en el proteasoma y, en el caso de una infección por un parásito intracelular (p. ej. virus, ciertas bacterias), absorben a péptidos derivados del patógeno. En ambos casos los péptidos (endógenos o microbianos) derivan del procesamiento citosólico del antígeno. Los péptidos resultantes de la degradación proteasómica son transportados al retículo endoplasmático rugoso (RER) para unirse a moléculas MHC de clase I recién formadas y que finalmente se exportan a la superficie celular a través del aparato de Golgi $^{50,52,53}$.

Las moléculas MHC de clase II se unen a péptidos derivados de antígenos exógenos, que previamente han sido captados por la célula presentadora mediante endocitosis o fagocitosis y se han proteolizado en fagolisosomas. Los péptidos exógenos se adsorben a las hendiduras de las moléculas de clase II que habían estado protegidas de la unión a péptidos durante su biosíntesis por el péptido CLIP de la cadena invariante $\mathrm{e}^{54}$.
Por tanto, existen dos tipos de rutas independientes para el procesamiento antigénico: la ruta citosólica y la ruta endocítica $^{51}$. De acuerdo con estos paradigmas una célula profesional presentadora de antígeno solamente podría presentar antígenos microbianos asociados a moléculas de clase I y por tanto reconocibles por linfocitos T citotóxicos, si ella misma está experimentando la traducción de proteínas del parásito intracelular. En otras palabras, si está infectada por el germen.

La primera evidencia de que debían existir fenómenos de transferencia antigénica entre células de la economía y células profesionales de la presentación antigénica tuvo la autoría de Michael Bevan ${ }^{55,56}$. En sus experimentos de transferencia de células hematopoyéticas idénticas en antígenos principales de histocompatibilidad (y por tanto en las moléculas presentadoras de clase I) podían inmunizar frente a antígenos menores de histocompatibilidad, derivados de variaciones en secuencias peptídicas de las proteínas codificadas por variantes alélicas en la misma especie presentes en células inyectadas. Sus experimentos concluyeron que células del receptor podían activar al sistema inmunitario presentando de modo subrogado los antígenos menores de histocompatibilidad presentes en las células del donante. El péptido presentado en estos experimentos es del donante mientras que la molécula de MHC presentadora es del receptor. El fenómeno recibió el nombre de activación cruzada (crosspriming) puesto que el resultado de la presentación antigénica era la activación linfocitaria (o priming) antígeno-específica. Ya se ha comentado que el resultado de la presentación antigénica puede ser tanto la activación como la represión de respuesta inmunitaria frente a un antígeno. En el caso de la presentación cruzada hablamos de crosspriming o crosstolerance, según sea el resultado funcional sobre los linfocitos específicos de antígeno. Hemos elegido los términos castellanos presentación cruzada o presentación subrogada para traducir el vocablo inglés crosspresentation. Esto es así porque subrogación quiere decir en castellano la delegación o reemplazo en las 
obligaciones y funciones hacia otros. El resultado final es la presentación de antígenos capturados o "exógenos" en moléculas de clase I. Esto es lo que hacen las células dendríticas con antígeno derivado de otras células.

Aunque la mayoría de las CD son capaces de captar antígenos y presentarlos a las células $\mathrm{T} \mathrm{CD}^{+}$vía $\mathrm{MHC}$ de clase II, la capacidad de procesar antígenos exógenos y presentarlos a células T CD8 ${ }^{+}$vía MHC de clase I parece que está más restringida. La presentación cruzada o subrogada es crucial para la generación de respuestas de linfocitos $\mathrm{T} \mathrm{CD}^{+}$citotóxicos en respuesta a patógenos intracelulares ${ }^{57}$. Los linfocitos T citotóxicos son capaces de destruir células tumorales sobre las que reconocen el antígeno para el que son específicos y esto determina el intenso estudio de estos mecanismos $^{58}$.

La presentación cruzada o subrogada es posible solamente en $\mathrm{CD}$ que muestran una adaptación de sus vías endocíticas para el procesamiento de antígeno ${ }^{57}$. Cuando una proteína o biopartícula es internalizada formándose endosomas, éstos frecuentemente se fusionan con lisosomas ricos en proteasas. En estos fagolisosomas la digestión proteolítica es usualmente muy activa, se potencia con el pH ácido (menor de 5) y es tan procesiva que no permite la formación de péptidos presentables por moléculas de MHC de clase I. Se piensa que en las células dendríticas el compartimento de los endosomas tempranos tiene peculiaridades que permiten el escape de polipéptidos al citoplasma, aunque no está bien aclarado qué mecanismo molecular es el que permite el acceso al citoplasma ${ }^{50}$. Se ha especulado con la baja actividad de las proteasas lisosomales por falta de acidificación, la inactivación de proteasas y la existencia de mecanismos de transporte activo en los que estaría implicada la proteína Sec $22^{59}$. Aunque la naturaleza bioquímica de la lanzadera entre endosoma y citoplasma es por el momento desconocida, es objeto de de una intensa investigación. Una evidencia experimental muy elegante, aunque indirecta, que sugiere su existencia fue propuesta por J. A. Villadangos al demostrar que deter- minados subtipos de CD sufren apoptosis cuando se las pone en presencia del factor proapoptótico citocromo $\mathrm{C}^{60}$. Esta sustancia solamente activa la apoptosis cuando se encuentra libre en el citosoplasma. Por tanto la inducción de apoptosis en la célula dendrítica indica que estas células han permitido el paso de proteína intacta, que adquirida mediante endocitosis, alcanza el citoplasma $^{60}$ (Fig. 1).

Las proteínas una vez liberadas al citoplasma son degradables por una proteinasa multicatalítica denominada proteasoma que está especializada en degradar polipéptidos no bien plegados y proteínas ubiquinadas. Experimentos con inhibidores del proteasoma han demostrado que es necesario un paso de digestión en este orgánulo citoplasmático para la presentación cruzada. Los péptidos producto de la digestión proteosómica son capturados por chaperonas que los transfieren a transportadores de péptidos selectivos (TAP-1/2) los cuales bombean los péptidos al interior del RER para ser cargados en moléculas de clase I que pueden anclarlas en su hendidura de unión (Fig. 1). Las células dendríticas carentes de TAP-1/2 no pueden presentar antígenos en moléculas de clase I y por tanto son incapaces de mediar presentación cruzada ${ }^{61}$.

El término presentación cruzada o subrogada se refiere a dos fenómenos potencialmente muy distintos entre sí. De un lado, la presentación de antígenos procedentes de la digestión de proteínas solubles endocitadas y, por otro lado, la presentación a partir de detritus celulares o restos apoptóticos habitualmente particulados $^{62}$. Aun cuando la mayor parte de la experimentación se ha realizado con proteínas purificadas como antígenos modelo desde el punto de vista de la fisiología de la respuesta inmunitaria, la presentación de antígenos procedentes de células necróticas o cuerpos apoptóticos parece mucho más relevante. Aunque el fenómeno de presentación cruzada se puede observar con varios tipos de células dendríticas aisladas o diferenciadas en cultivo, existen subpoblaciones altamente especializadas en desempeñar estas funciones moleculares en un contexto relevante. 


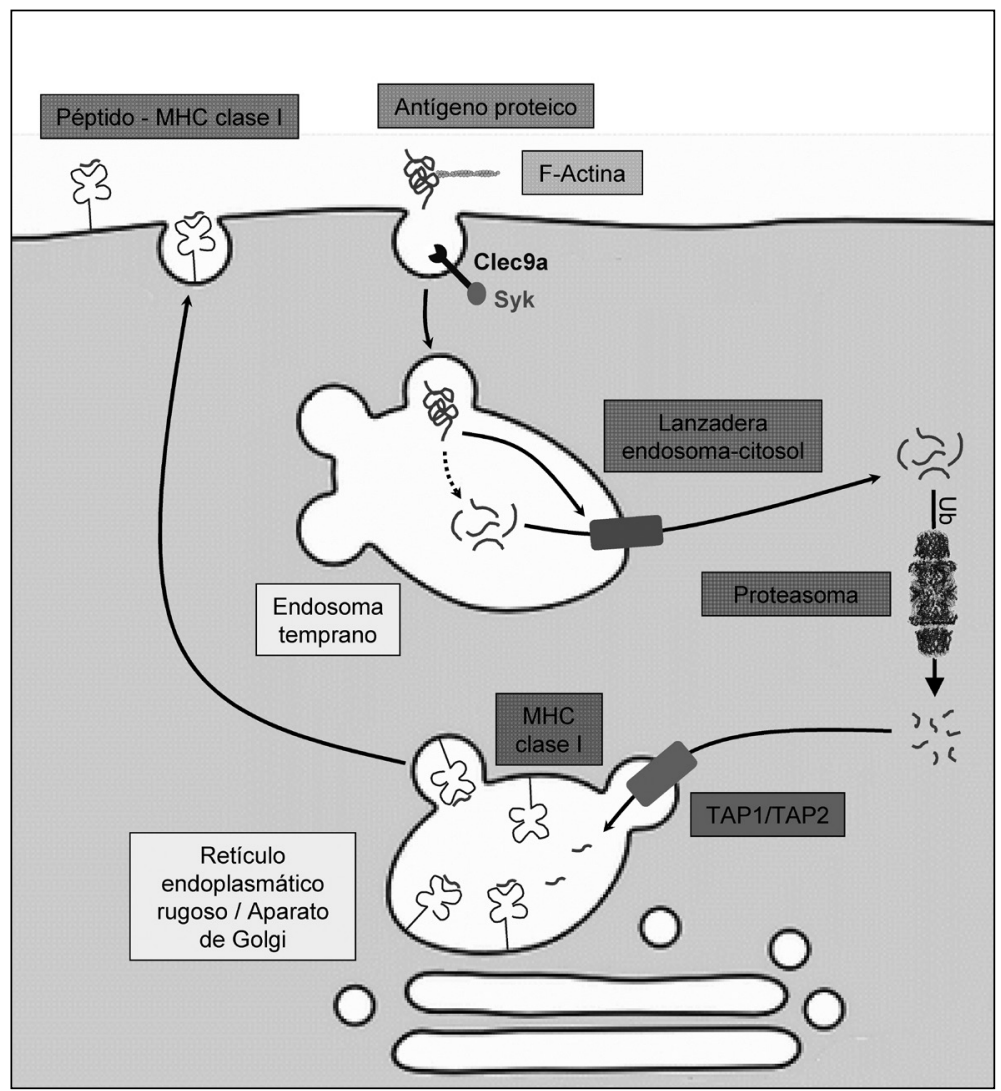

Figura 1. Mecanismos de presentación cruzada o subrogada a partir de restos celulares necróticos.

Esto es especialmente relevante si pensamos que el sistema inmunitario ha evolucionado para defender al organismo de parásitos intracelulares que destruyen a las células a las que infectan. Al morir las células infectadas dejarían entre sus restos antígenos relevantes del germen patógeno. Dependiendo del contexto microbiológico e inflamatorio, la presentación cruzada o subrogada puede dar lugar a una respuesta inmunitaria o a tolerancia antígeno específica. La inoculación de una proteína purificada sin adyuvante, daño celular o gérmenes tiende a inducir tolerancia, es decir falta de respuesta frente a ese antígeno. Además la relativa ineficiencia del fenómeno de presentación de antígenos traducidos por otra célula posibilita que antígenos de bajo ni- vel de expresión puedan ser ignorados por el sistema inmunitario sin inducción de inmunidad ni tolerancia en lo que se ha dado en denominar ignorancia inmunológica ${ }^{63}$.

\section{DETECCIÓN DE PATRONES MOLECULARES VIRALES POR CÉLULAS DENDRÍTICAS ESPECIALIZADAS EN PRESENTACIÓN CRUZADA O SUBROGADA}

La maduración de las CD es un programa de expresión génica cuyos productos determinan la capacidad de activar a linfocitos $\mathrm{T}$ y linfocitos NK. El programa madurativo puede ser inducido en respuesta a una lista de estímulos tanto microbianos 
como proinflamatorios. Estos pueden incluir patrones moleculares asociados a gérmenes, citoquinas pro-inflamatorias (ej: TNF- $\alpha$ e IFN de tipo I), inmuno-complejos y señales moleculares liberadas o generadas durante un daño tisular ${ }^{64-66}$. Los patrones moleculares asociados a patógenos (PAMP) quizá son los estímulos más potentes y su descubrimiento ha ofrecido la posibilidad de desarrollar nuevos adyuvantes para vacunas $^{64-66}$. Estos PAMP son reconocidos por receptores del sistema inmune innato denominados receptores de reconocimiento de patrones (RRP), que incluyen lectinas tipo C de superficie (CLR), receptores tanto de superficie como endósomicos tipo Toll (TLR) y receptores citosólicos como el RIG-I, MDA-5 y NLR ${ }^{64}$. Los receptores de reconocimiento de patrones moleculares de gérmenes se expresan en muchas células efectoras del sistema inmune innato, macrófagos, células dendríticas, y células B activadas, incluidas en el concepto de células presentadoras de antígeno ${ }^{33}$. No se trata de receptores específicos de antígeno, ya que no presentan una distribución clonal ${ }^{67}$, sino de detectores de la presencia de biomoléculas que denotan la presencia de gérmenes y la estirpe filogenética de los mismos.

Tras la infección de un virus, las células del sistema inmunitario tales como las CD y los macrófagos, detectan el ARN de doble cadena (dsRNA) viral a través de los receptores RLRs y TLR3 ${ }^{68}$. RIG-I y MDA5 pueden detectar los ácidos nucleicos de virus ARN en el citosol ${ }^{68}$. RIG-I detecta características del ARN de varios virus pertenecientes a los géneros de paramixovirus, ortomixovirus, flavivirus y rhabdovirus y MDA5 detecta ARN de picornavirus y calicivirus ${ }^{69,70}$. Tras la detección se activa un complejo con la proteína IPS-1 (también denominada MAVS) de la superficie mitocondrial y la activación de los factores IRF inductores de interferón tipo I, vía la tirosina quinasa TBK-1 ${ }^{32}$ e IKK $\varepsilon$. TLR3 reconoce dsRNA en el interior de endosomas e inicia la transducción de señales a través de su dominio intracitoplasmático que interacciona con el adaptador TRIF ${ }^{69,70}$.

El ácido poliinosínico-policitidílico (poly I:C) es un análogo de ARN de doble cadena y el tratamiento de animales con poly I:C induce intensos efectos antivirales y antineoplásicos ${ }^{71}$, interpretados originalmente como el resultado de la producción de IFN- $\alpha$. Las células dendríticas $\mathrm{CD} 8 \alpha^{+}$expresan los genes para IFN tipo I, IL-6, e IL12 p40 en respuesta a poly I:C. El poly I:C, actuando como una análogo de ARN viral, activa el eje RIG-I / IPS-1 en el citosol ${ }^{32,71}$. Poly I:C es agonista tanto de TLR-3 como de RIG-I, de manera que puede inducir la maduración de CD tanto desde endosomas fagocíticos como desde el citoplasma ${ }^{32,70,71}$. Dado que la misión fisiológica de los linfocitos $\mathrm{T}$ citotóxicos es la defensa frente a infecciones virales, parece lógico que la presentación cruzada se intensifique en presencia de ARN viral.

\section{SUBPOBLACIONES DE CÉLULAS DENDRÍTICAS DE RATÓN ESPECIALIZADAS EN PRESENTACIÓN CRUZADA O SUBROGADA}

Se reconocen tanto en ratón como en humano varias subpoblaciones de células dendríticas distinguibles por sus marcadores de superficie, su ontogenia y sus funciones $^{72-74}$. En el bazo de ratón es posible realizar una división en dos subpoblaciones diferentes atendiendo al marcador CD8 $\alpha$. De esta manera, las CD se pueden clasificar en dos grandes subgrupos con distintas funciones biológicas: $\mathrm{CD} 8 \alpha^{+} / \mathrm{CD} 11 \mathrm{c}^{+} \mathrm{y}$ $\mathrm{CD} 8 \alpha / \mathrm{CD} 11 \mathrm{c}^{+}$.

Las células dendríticas de la "familia $\mathrm{CD} 8 \alpha^{+}$" representan aproximadamente el $20 \%$ de las CD convencionales del bazo en ratón ${ }^{75}$. Existe evidencia experimental in vivo que indica que estas células captan material exógeno para presentarlo asociado a MHC de clase I, lo que permite respuestas T citotóxicas frente a virus y tumores $^{72,74,76}$. Asimismo, expresan receptores de membrana que les permiten internalizar eficientemente material de células muertas o en apoptosis ${ }^{77,78}$. Como sucede con otras poblaciones de CD las células $\mathrm{CD} 8 \alpha^{+}$, en su estado inmaduro, expresan cantidades escasas de moléculas de co-estimulo, como CD80 y CD86 ${ }^{79}$. 
A diferencia de los linfocitos T citotóxicos que expresan el dímero $\mathrm{CD} 8 \alpha / \mathrm{CD} 8 \beta$, estas células disponen del homodímero $\mathrm{CD} 8 \alpha / \mathrm{CD} 8 \alpha^{80}$, que es un co-receptor que interacciona con moléculas MHC de clase I pero su función en $\mathrm{CD}$ es desconocida y no se conserva en humanos.

En ratón se ha descrito la subpoblación $\mathrm{CD} 8 \alpha^{+}$localizada en sangre y en órganos linfoides secundarios y la subpoblación $\mathrm{CD} 103^{+}$en la dermis ${ }^{75,81}$ (Fig. 2 y Tabla 1). Ambas poblaciones expresan marcadores comunes (tales como Clec9a) y dependen para su ontogenia del factor de transcripción Batf $3^{82,83}$. Los ratones modificados genéticamente que carecen de este factor de transcripción carecen de células dendríticas $\mathrm{CD} 8 \alpha^{+}$en el bazo y en los ganglios lin- fáticos, mientras que los números de otros subtipos de CD se mantienen intactos. La ausencia de Batf3 conlleva que los ratones tengan una respuesta más débil frente a infecciones virales y una mayor incidencia de tumores espontáneos ${ }^{82,83}$. Además de la necesidad del factor de transcripción Batf3 para la diferenciación de las CD de ratón, se ha observado que la carencia del factor de transcripción IRF-8 determina la ausencia en el ratón tanto de células dendríticas plasmocitoides como de células dendríticas $\mathrm{CD} 8 \alpha^{84}$. Existe además una cepa de ratón llamada BXH2 que porta una mutación puntual en el gen de IRF-8 y que determina la ausencia de las células $\mathrm{CD} 8 \alpha$, mientras que las $C D$ plasmocitoides son aparentemente normales ${ }^{85}$.

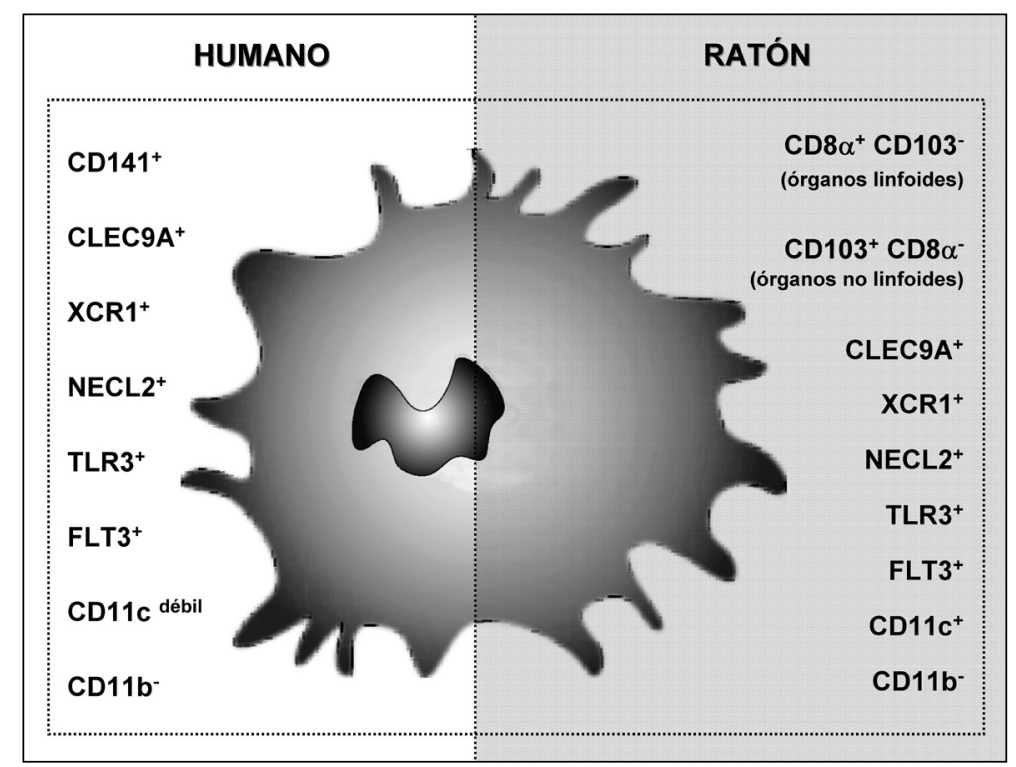

Figura 2. Comparación de los marcadores de células dendríticas especializadas en presentación cruzada o subrogada de ratón y humano.

Es muy sorprendente que las células $\mathrm{CD} 8 \alpha^{+}$de ratón residen en órganos linfoides sin patrullar los tejidos periféricos como la piel y las mucosas. El paradigma de la captura de antígeno en el tejido y subsecuente presentación linfocitaria en órganos linfoi- des no parece por tanto posible con esta distribución tisular. Existe un debate en la comunidad científica sobre el mecanismo que hace llegar aquellos antígenos que van a ser presentados hasta el órgano linfoide secundario. Es posible que ocurra presen- 
tación antigénica de segunda mano y que las células $\mathrm{CD} 8 \alpha^{+}$estén especializadas en presentar antígenos capturados por otras CD o macrófagos que sí provengan de fo$\cos$ inflamatorios ${ }^{86,87}$. La función de estas células $\mathrm{CD} 8 \alpha^{+}$es crítica para la inmunización con conjugados de anticuerpos monoclonales frente a la proteína DEC-205 y antígenos modelo ${ }^{88}$.

La expresión selectiva en la superficie celular de la lectina Clec9a en este subgrupo de células dendríticas ha permitido usar este receptor como diana para dirigir antígenos tumorales frente a estas subpoblaciones de dendríticas, resultando en una inducción muy eficiente de actividad citotóxica frente a antígenos modelo y frente a antígenos tumorales ${ }^{88,89}$. La experimentación con este subtipo celular es difícil debido a la complejidad para purificarlas en número suficiente a partir de bazos de ratones. Es posible emplear una estrategia basada en la infusión de la citoquina sFlt-3L (fms-related tyrosine kinase 3 ligand) que permite expandir esta subpoblación en número suficiente de forma que se pueda purificar estas células por selección inmunomagnética para experimentar sobre ellas ${ }^{90}$.

Una alternativa que permite estudiar este tipo de células dendríticas es el cultivo de suspensiones celulares de médula ósea con la citoquina sFlt-3L $\mathrm{L}^{91}$. Aunque el sFlt-3L es la única citoquina exógena añadida al cultivo, la diferenciación depende de trazas de GM-CSF producido endógenamente $^{92}$. Una fracción de las CD resultantes tienen propiedades funcionales similares a las células $C D 8 \alpha^{+}$de bazo, aunque carecen de la expresión de CD8 $\alpha$ en su superficie. Estas CD generadas en los cultivos expresan altos niveles de Clec9A y niveles bajos de CD172a, en comparación con las células CD8 $\alpha^{+}$del bazo. La estimulación de estas células con ligandos de receptores Tolllike (TLR), previa a la captura antigénica, incrementa en gran medida la eficiencia de la presentación cruzada ${ }^{93,94}$. Una serie de estudios publicados recientemente demuestran que los precursores circulantes del linaje de las $\mathrm{CD} 8 \alpha^{+}$no están dotadas de la capacidad de realizar la presentación cruzada de antígenos y que dicha capacidad se adquiere en pasos posteriores del desarrollo una vez desplegadas en el tejido linfoide ${ }^{75,78}$.

Por contraposición con el bazo, las células $\mathrm{CD} 8 \alpha^{+}$del timo representan la mayor parte de la población de dendríticas residentes en este órgano ${ }^{75}$. Las células $\mathrm{CD} 8 \alpha^{+}$ residentes en el timo expresan Clec9A, CD205, CD24, así como CD11b y CD172a a niveles bajos. También expresan bajos niveles de moléculas de co-estímulo y niveles moderados de MHC clase II. Sin embargo, difieren en que expresan establemente $\mathrm{CD}_{103}{ }^{92}$. La molécula CD103 es un receptor de "homing" a tejidos epiteliales ${ }^{81,83}$. La importancia de la presentación cruzada en el timo es un tema en debate. Se puede especular que la captura y presentación de antígenos en restos apoptóticos de timocitos $\mathrm{u}$ otras células tímicas puede ser importante en fenómenos de selección negativa implicados en eliminar del repertorio de reconocimiento a linfocitos $\mathrm{T}$ citotóxicos con capacidad autorreactiva. No obstante, por el momento no se dispone de evidencia experimental.

El hecho de que las células de la "familia $\mathrm{CD} 8 \alpha^{+}$" sean aquellas que parecen tener más acentuada esta capacidad, no significa que las células $\mathrm{CD} 8 \alpha^{-}$no sean capaces de realizar la presentación cruzada en ninguna circunstancia ${ }^{62}$. Existen estudios experimentales que indican que se puede conseguir presentación cruzada por parte de la subpoblación CD $8 \alpha$ mediante su activación a través de TLRs o FcR ${ }^{95-98}$ y se ha observado que son necesarias para la presentación cruzada de antígenos derivados de Saccharomyces cerevisae ${ }^{99}$ (Tabla 1).

Las células dendríticas $\mathrm{CD}_{11 \mathrm{c}^{+} \text {deriva- }}$ das de suspensiones de médula ósea en cultivos de diferenciación en presencia de GM-CSF son capaces de presentar antígenos proteicos o en cuerpos apoptóticos fagocitados a linfocitos $\mathrm{T}$ citotóxicos con efectos terapéuticos frente a tumores ${ }^{100}$ (Tabla 1). 
Tabla 1. Esquema de los diferentes subtipos de células dendríticas de ratón en bazo y piel y sus funciones en inmunidad. DC: células dendríticas; LC: células de Langerhans; cDC: células dendríticas convencionales; pDC: células dendríticas plasmocitoides; +/-: baja capacidad y sólo en ciertas situaciones; ++: alta capacidad.

\begin{tabular}{|c|c|c|c|c|c|c|}
\hline \multicolumn{7}{|c|}{ Ratón } \\
\hline \multicolumn{5}{|c|}{ Bazo } & \multicolumn{2}{|c|}{$\begin{array}{c}\text { Piel } \\
\text { (ejemplo de tejido periférico) }\end{array}$} \\
\hline & $\mathrm{cDCs}$ & & \multicolumn{2}{|c|}{$\begin{array}{c}\mathrm{pDCs} \\
\left(\mathrm{CD} 11 \mathrm{c}^{+} \mathrm{B} 220^{+} \mathrm{PDCA}^{+} \mathrm{1}^{+}\right)\end{array}$} & $\begin{array}{c}\text { LC } \\
\left(\text { Langerina }^{+}\right)\end{array}$ & DC dermal \\
\hline $\begin{array}{c}\text { CD } 8 \alpha^{+} \text {CD } 4- \\
\text { CD11b }^{-} \text {CD } 205^{+}\end{array}$ & $\begin{array}{c}\mathrm{CD} 8 \alpha^{-} \mathrm{CD}^{+} \\
\mathrm{CD}^{+} 1 \mathrm{~b}^{+} \mathrm{CD} 205^{+}\end{array}$ & $\begin{array}{c}\mathrm{CD}^{-} \mathrm{CD}^{-} \\
\mathrm{CD} 11 \mathrm{~b}^{-} \\
\mathrm{CD}^{-} 05^{+}\end{array}$ & $\begin{array}{c}\text { CD9+ }^{+} \\
\text {Siglec }^{\text {bajo }}\end{array}$ & CD9-Siglec ${ }^{\text {bajo }}$ & $\begin{array}{l}\mathrm{CD}_{11 \mathrm{~b}^{+}} \mathrm{CD} 103- \\
\mathrm{CD}^{-} 72 \mathrm{a}^{+} \mathrm{CD} 205^{+} \\
\text {Dectina- }^{+}\end{array}$ & $\begin{array}{l}\mathrm{CD}^{11 b^{\text {low }}} \mathrm{CD}^{-103^{+}} \\
\mathrm{CD}^{+} 12 \mathrm{a}^{+} \mathrm{EpCAM}^{-}\end{array}$ \\
\hline $\begin{array}{l}\text { - Respuesta Th1 } \\
\text { - Presentación } \\
\text { subrogada }\end{array}$ & $\begin{array}{l}\text { - Respuesta T } \\
\text { helper } \\
\text { - Activación } \\
\text { células T CD4+ }\end{array}$ & $\begin{array}{l}\text { Respuesta T } \\
\text { helper }\end{array}$ & $\begin{array}{l}\text { Producción } \\
\text { de IFN- } \alpha / \beta\end{array}$ & $\begin{array}{l}\text { Inducción de } \\
\text { linfocitos T } \\
\text { reguladores } \\
\text { FoxP3 }^{+} \mathrm{CD}^{+}\end{array}$ & $\begin{array}{l}\text { - Respuesta } \\
\text { celular en la piel } \\
\text { - Rechazo de } \\
\text { injertos }\end{array}$ & $\begin{array}{l}\text { Presentación } \\
\text { subrogada }\end{array}$ \\
\hline \multicolumn{7}{|c|}{ Capacidad de presentación subrogada } \\
\hline++ & $+/-$ & $+/-$ & $+/-$ & $+/-$ & $+/-$ & ++ \\
\hline
\end{tabular}

Las células de Langerhans (Langerina ${ }^{+}$ $\mathrm{CD}_{11 \mathrm{c}^{+}}$) en la piel están desplegadas en la epidermis donde pueden capturar antígenos y se sabe que son capaces de migrar a ganglios linfáticos con material celular endocitado. Existen estudios experimentales en los que estas células demuestran capacidad de presentar a linfocitos T citotóxicos en particular en infecciones experimentales con virus HSV-1 ${ }^{81}$ (Tabla 1).

Muy recientemente se ha descrito un ratón transgénico Knock-in que va a ser de extraordinaria utilidad en el esclarecimiento de la fisiología de estas células profesionales de la presentación cruzada. En estos ratones se ha insertado en el locus del receptor de quimioquinas XCR1 el gen de una proteína fluorescente fusionada con el receptor de toxina diftérica. Este ratón permite realizar experimentos de seguimiento de estas poblaciones celulares que son selectivamente fluorescentes y deplecionar transitoriamente al ratón de estas poblaciones celulares mediante la administración de toxina diftérica a bajas dosis. Los experimentos realizados en estos ratones tras depleción confirman que desaparecen selectivamente durante 2-4 días las células $\mathrm{CD} 8 \alpha^{+}$del bazo/ganglio y las células CD103+ de la piel. En esas condiciones se confirma el papel crítico y no redundante de estas CD en la inducción de linfocitos T citotó$\operatorname{xicos}^{101}$.

\section{CÉLULAS DENDRÍTICAS HUMANAS ESPECIALIZADAS EN PRESENTACIÓN CRUZADA O SUBROGADA}

Durante casi una década, el problema ha sido que no era posible identificar una población de células dendríticas humanas con características similares a las de las células dendríticas $\mathrm{CD} 8 \alpha^{+}$de ratón, ya que no existe una población que co-exprese $\operatorname{CD} 8 \alpha$ y no es fácil obtener órganos linfoides humanos con viabilidad celular. Sin embargo, el trabajo del Dr. David Sancho, en el grupo del Dr. Caetano Reis e Sousa, permitió demostrar que existe una población con un perfil transcriptómico similar en humanos y en ratón ${ }^{89,102}$. Estos investigadores partieron de comparaciones transcriptómicas entre células $\operatorname{CD} 8 \alpha^{+}$de ratón con el resto de poblaciones dendríticas, identificando genes diferencialmente expresados. De entre estos genes, dos de ellos destacaban, puesto que debían expresarse en la membrana y era posible reconocerlos me- 
diante anticuerpos monoclonales. Uno de ellos era la lectina tipo C, Clec9A (DNGR1). Obteniendo anticuerpos anti-Clec9A fue posible identificar esta subpoblación en humanos y demostrar que en sangre periférica coincide con la previamente descrita por expresar el marcador BDCA-3 (CD141 o trombomodulina) ${ }^{103}$.

Recientemente, se ha confirmado que las células dendríticas BDCA- $3^{+}$humanas son funcionalmente equivalentes a las de la "familia $\mathrm{CD} 8 \alpha^{+}$" de ratón ${ }^{102,104-107}$. En una primera descripción funcional se muestra que son superiores en su capacidad de presentación cruzada y en la generación de respuestas efectoras $\mathrm{T} \mathrm{CD}^{+}$frente a antígenos exógenos ${ }^{102,106,107}$. Las células BDCA- $3^{+}$humanas comparten las siguientes propiedades con las células $C D 8 \alpha^{+}$de ratón:

1. Expresan un patrón común de receptores: comparten la expresión de Clec9a (receptor de la familia 9 del dominio de tipo C de lectina) $)^{102,108}$, Necl2 (CADM1 o molécula 1 de adhesión celular $)^{102,107}$, TLR-3 $3^{107}$ $\mathrm{y}$ el receptor de quimioquinas XCR $1^{104,109}$ (Fig. 2).

2. Dependen de los mismos factores de transcripción (Batf3, IRF-8).

3. Están especializadas en la captación de células necróticas.

4. Son productoras de IL-12 e IFN $\alpha^{110}$.

5. Tienen la capacidad de presentación cruzada o subrogada, lo que resulta potencialmente en la activación CTL.

La expresión selectiva del receptor de quimioquinas XCR1 sugiere un compartimento sumamente interesante en migración ${ }^{106,109}$. Solamente existe un ligando conocido, la quimioquina XCL1, que es producida por linfocitos T CD8 activados. De esta manera es muy posible que ambas poblaciones celulares estén hechas para encontrarse en el tumultuoso órgano linfoide en el que se mueven, de forma que la probabilidad de ejercer presentaciones cruzadas o subrogadas de antígeno es posiblemente superior a lo predecible por la escasez relativa de ambos subtipos celulares. Sin embargo, la capacidad para activar CTL de las células $\mathrm{BDCA}-3^{+}$resulta quizá menos notoria que las células $\mathrm{CD} 8 \alpha^{+}$de ratón y ne- cesitan ser inducidas por ligandos de TLR, como poly I: $\mathrm{C}^{102,111}$. Las células BDCA-3 $3^{+}$de sangre periférica podrían representar un equivalente de un linaje temprano de las células $\mathrm{CD} 8 \alpha^{+}$de ratón, para las que son necesarios factores adicionales para inducir eficientemente la capacidad de realizar la presentación cruzada de antígenos ${ }^{112}$. En trabajos posteriores se han identificado combinaciones de factores de crecimiento que permiten enriquecer en cultivo estas células pero con un bajo rendimiento/ pureza y elevada complejidad metodológica $^{113,114}$.

Existe controversia sobre si, en ausencia de activación, la población BDCA-1 ${ }^{+}$, las pDC y las LC también son capaces de realizar la presentación cruzada de antígenos en el contexto de proteínas solubles. Todas estas poblaciones de CD tienen la capacidad de exportar proteínas internalizadas al citoplasma, paso clave para la presentación cruzada ${ }^{50}$. Estudios comparativos de células BDCA- $1^{+}$y BDCA- $3^{+}$aisladas de sangre periférica y de amígdalas demuestran que ambas tienen la capacidad de presentar antígeno exógeno a clones de linfocitos $\mathrm{T}$ en cultivo ${ }^{113}$. Es más cuestionable si las células BDCA- $1^{+}$son capaces de direccionar los antígenos internalizados a partir de restos celulares a endosomas tempranos y si esto permite su presentación cruzada o subrogada (Tabla 2).

Las células BDCA-3 $3^{+}$son las únicas que presentan la molécula Clec9A en su superficie, que resulta fundamental en el reconocimiento de las células necróticas para que pueda darse la presentación cruzada. De hecho, David Sancho pudo demostrar que el sistema Clec9A es necesario y no redundante para la captación de antígenos a partir de células necróticas en ratón ${ }^{115}$. Así, el receptor es crítico para poder presentar antígenos virales presentes en cuerpos apoptóticos como se demuestra en un sistema de infección por virus vaccinia $^{116,117}$.

La endocitosis mediada por receptores puede ser también realizada a través de otras lectinas de tipo C. A este grupo pertenecen DEC-205, el receptor de manosa (MR), la dectina-1, DC-SIGN y DCIR ${ }^{28,118}$. 
Tabla 2. Esquema de los diferentes subtipos de células dendríticas de humano en sangre y piel y sus funciones en inmunidad. LC: células de Langerhans; cDC: células dendríticas convencionales; pDC: células dendríticas plasmocitoides; +/-: baja capacidad y sólo en ciertas situaciones; ++: alta capacidad.

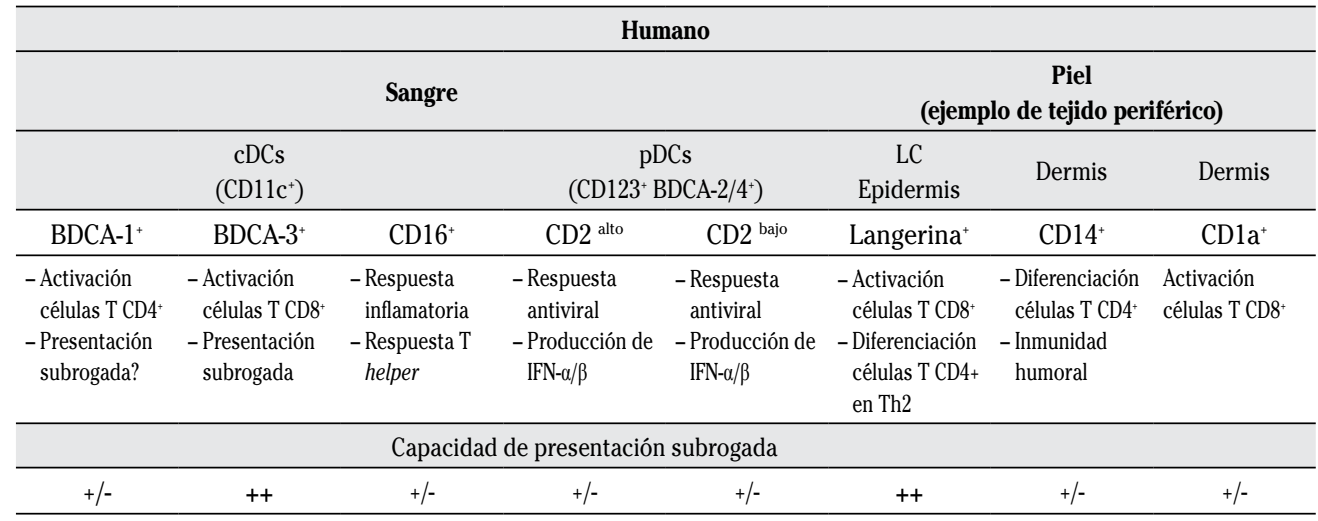

Steinman y su grupo identificaron que la función presentadora de antígeno de las CD estaba asociada con la expresión de DEC-205 (CD205), una proteína de membrana homóloga al receptor de manosa de macrófago, implicada en endocitosis ${ }^{119}$. La unión de la proteína a DEC-205 resulta en una rápida internalización a endosomas ricos en MHC de clase II. El papel de DEC205 en la captación de antígeno y presentación cruzada se ha demostrado en CD de ratón ${ }^{120}$. DEC-205 se expresa en muchas subpoblaciones de $\mathrm{CD}$ pero cuando se hace diana un antígeno a DEC-205 mediante inmunoconjugados la única subpoblación que inmuniza a linfocitos $\mathrm{T}$ CD8 ${ }^{+}$es la subpoblación $\mathrm{CD} 8 \alpha^{+}$. Es objeto de debate si estas observaciones dependen del hecho de que DEC-205 se internaliza a endosomas tempranos estables ${ }^{114}$. De hecho, las células BDCA-3+ tienen una mayor capacidad de realizar la presentación cruzada de aquellos antígenos dirigidos a endosomas tempranos, como se ha podido observar al utilizar un anticuerpo que señalice a través de DEC-205 conjugado con el antígeno ${ }^{114}$.

DC-SIGN fue originalmente identificado como un receptor de ICAM-3, que producía la proliferación de células $\mathrm{T}^{121}$. Este receptor es capaz de interaccionar con muchos patógenos, incluídos HIV, Mycobacterium y $E$ coli $^{122}$. Su papel en internalización de an- tígeno es objeto de controversia y no existe evidencia de su implicación en presentación cruzada.

\section{ESTRATEGIAS PARA LA EXPLOTACIÓN TERAPÉUTICA DE CÉLULAS DENDRÍTICAS PROFESIONALES DE LA PRESENTACIÓN CRUZADA O SUBROGADA}

Las estrategias de inmunoterapia están comenzando a demostrar eficacia parcial en el tratamiento de pacientes con cáncer $^{123-125}$. La inmunoterapia con células dendríticas se basa en aprovechar las propiedades de estas células para presentar antígeno de forma inmunogénica y así reprogramar y activar la respuesta de linfocitos $\mathrm{T}$ con capacidad tumoricida ${ }^{123,124,126}$. Actualmente, la tecnología más extendida de inmunoterapia frente al cáncer con células dendríticas consiste en inocular células extraídas del paciente, cultivadas in vitro, cargadas con antígenos tumorales relevantes, activadas (maduradas) para ser pro-inmunogénicas y reinfundidas en el paciente para inducir una respuesta inmune antitumoral.

El uso de la subpoblación de dendríticas humanas BDCA-3+, hasta ahora pobremente explorada en clínica, podría resul- 
tar en una respuesta efectora T citotóxica superior, como se ha demostrado con sus equivalentes murinos (Alfaro y col, manuscrito en preparación). Sin embargo por el momento no se ha podido generar ningún protocolo eficiente para separar o diferenciar con rendimiento razonable estas células a partir de sus precursores, aunque se ha realizado como ya hemos referido algún intento con escaso rendimiento ${ }^{113,114}$.

La eficacia en modelos de ratón y los conocimientos disponibles sobre las propiedades funcionales de esta subpoblación de células dendríticas indica que son las más apropiadas para la inducción de respuestas $\mathrm{T}$ citotóxicas frente a tumores y que por tanto resultarían en estrategias terapéuticas más eficaces. Existen dos aproximaciones posibles para inducir la respuesta a través de estas células dendríticas: (i) intentar dirigir antígenos al interior de estas células mediante proteínas de fusión dianizadas. Esta aproximación es prometedora pero, por el momento, presenta la dificultad de identificar que neoantígenos tumorales se pueden utilizar para la inducción de inmunidad antitumoral eficiente y (ii) proceder al aislamiento y manipulación de estas células ex vivo. Las células se purifican de los pacientes, se cargarían con antígeno tumoral para ser activadas (maduradas) y posteriormente se inyectarían por vía percutánea, intravenosa o en el interior de ganglios linfáticos localizados mediante ecografía.

La primera estrategia consiste en dirigir antígenos a receptores de la superficie celular específicos de las CD eficientes en captar antígeno para su presentación cruzada (DEC-205, CLEC9A). Por un lado, sabemos que la inmunización con antígenos dirigidos a la población homóloga $\mathrm{CD} 8 \alpha^{+} \mathrm{de}$ ratón es una estrategia efectiva para obtener inmunidad anti-tumoral ${ }^{127}$. La cuestión ahora es si se pueden realizar enfoques parecidos para dirigir antígenos al homólogo humano, alcanzando resultados terapéuticos significativos.

La segunda estrategia consiste en la selección de las células BDCA- $3^{+}$y su posterior manipulación ex vivo. Los pacientes se someterían a una leucocitoaféresis. Sus CD son separadas mediante inmunoselección, se cultivan en medios que contengan ciertos antígenos de interés y posteriormente se inyectan de nuevo al paciente. De la misma forma cabe mencionar el uso de sFLT-3L por su capacidad de multiplicar el número de células disponibles para su posterior aislamiento y manipulación, por lo que podría generarse un mayor número de células movilizadas con este método, lo que puede ser técnicamente necesario para hacer viable la estrategia. La inyección intratumoral de estas células es también una estrategia con posibilidades de éxito, sobretodo si se provoca la muerte de células malignas en el territorio de la inyección ${ }^{87}$. Parece plausible que las células dendríticas profesionales de la presentación cruzada elegirán, entre el debris celular, los antígenos tumorales más susceptibles de ser presentados ${ }^{128}$.

El tipo de agonista de TLR suministrado para inducir maduración también desempeña un papel muy importante en la calidad y el tipo de respuesta inmunitaria generada. Por ejemplo, la estimulación tanto con TLR3, TLR7 o TLR9 induce la producción de IFN tipo I, que permite mejorar aún más la presentación cruzada por parte de las CDs ${ }^{129}$. Del mismo modo, la estimulación con ligandos para TLR3, TLR4, TLR7 y TLR9 induce la producción de IL-12p7033. La estimulación de las células dendríticas mediante múltiples tipos de agonistas de TLR, en combinación unos con otros, parece ser uno de los medios más eficientes en la inducción de la maduración y en la estimulación de la presentación cruzada.

Es probable que la próxima generación de vacunas orientadas a conseguir linfocitos T citotóxicos explote las funciones especializadas de las células $\mathrm{BDCA}^{+}$y posiblemente incorpore formulaciones con diferentes tipos de ligandos de TLR como adyuvantes moleculares. El objetivo es una presentación cruzada muy eficiente inmunizando frente a los antígenos tumorales relevantes.

\section{BIBLIOGRAFÍA}

1. Steinman RM, Cohn ZA. Identification of a novel cell type in peripheral lymphoid organs of mice. I. Morphology, quantitation, tissue distribution. J Exp Med 1973; 137: 1142-1162. 
2. STEINMAn RM, CoHn ZA. Identification of a novel cell type in peripheral lymphoid organs of mice. II. Functional properties in vitro. J Exp Med 1974; 139: 380-397.

3. Steinman RM, Lustig DS, Cohn ZA. Identification of a novel cell type in peripheral lymphoid organs of mice. 3. Functional properties in vivo. J Exp Med 1974; 139: 1431-1445.

4. Lanzavecchia A, Sallusto F. Ralph M. Steinman 1943-2011. Cell 2011; 147: 1216-1217.

5. Inaba K. A tribute to Ralph M. Steinman. Int Immunol 2012; 24: 1-3.

6. Steinman RM. Dendritic cells: understanding immunogenicity. Eur J Immunol 2007; 37 Suppl 1: S53-60.

7. ARDAVIN C. Origin, precursors and differentiation of mouse dendritic cells. Nat Rev Immunol 2003; 3: 582-5890.

8. Steinman RM. Decisions about dendritic cells: past, present, and future. Annu Rev Immunol 2012; 30: 1-22.

9. Banchereau J, Steinman RM. Dendritic cells and the control of immunity. Nature 1998; 392: 245-252.

10. Steinman RM, Hawiger D, Liu K, Bonifaz L, BonnYAY D, MAHNKE K et al. Dendritic cell function in vivo during the steady state: a role in peripheral tolerance. Ann N Y Acad Sci 2003; 987: $15-25$.

11. Dzopalic T, Rajkovic I, Dragicevic A, Colic M. The response of human dendritic cells to co-ligation of pattern-recognition receptors. Immunol Res 2012; 52: 20-33.

12. Liu YJ, Kanzler H, Soumelis V, Gilliet M. Dendritic cell lineage, plasticity and cross-regulation. Nat Immunol 2001; 2: 585-589.

13. UnderhILl DM, GoOdRIDGe HS. Information processing during phagocytosis. Nat Rev Immunol 2012; 12: 492-502.

14. Hopkins RA, Connolly JE. The specialized roles of immature and mature dendritic cells in antigen cross-presentation. Immunol Res 2012; 53: 91-107.

15. Heath WR, Villadangos JA. No driving without a license. Nat Immunol 2005; 6: 125-126.

16. Hespel C, Moser M. Role of inflammatory dendritic cells in innate and adaptive immunity. Eur J Immunol 2012; 42: 2535-2543.

17. Macagno A, Napolitani G, Lanzavecchia A, Sallusто F. Duration, combination and timing: the signal integration model of dendritic cell activation. Trends Immunol 2007; 28: 227-233.

18. Muller JR, Waldmann TA, Kruhlak MJ, Dubois S. Paracrine and transpresentation functions of IL-15 are mediated by diverse splice versions of IL-15Ralpha in human monocytes and dendritic cells. J Biol Chem 2012; 287: 40328-40338.

19. SteEl JC, Waldmann TA, Morris JC. Interleukin-15 biology and its therapeutic implications in cancer. Trends Pharmacol Sci 2012; 33: $35-41$.

20. Hervas-Stubbs S, Perez-Gracia Jl, Rouzaut A, Sanmamed MF, Le Bon A, Melero I. Direct effects of type I interferons on cells of the immune system. Clin Cancer Res 2011; 17: 2619-2627.

21. Hervas-Stubbs S, Mancheno U, Riezu-Bou JI, LaRRAGa A, Ochoa MC, Alignani D et al. CD8 T cell priming in the presence of IFN-alpha renders CTLs with improved responsiveness to homeostatic cytokines and recall antigens: important traits for adoptive $\mathrm{T}$ cell therapy. $\mathrm{J}$ Immunol 2012; 189: 3299-3310.

22. Zelante T, Fric J, Wong AY, Ricciardi-Castagnoli P. Interleukin-2 production by dendritic cells and its immuno-regulatory functions. Front Immunol 2012; 3: 161.

23. ReIS E Sousa C. Activation of dendritic cells: translating innate into adaptive immunity. Curr Opin Immunol 2004; 16: 21-25.

24. Dieu-Nosjean MC, Vicari A, Lebecque S, Caux C. Regulation of dendritic cell trafficking: a process that involves the participation of selective chemokines. J Leukoc Biol 1999; 66: 252-262.

25. Forster R, Davalos-Misslitz AC, Rot A. CCR7 and its ligands: balancing immunity and tolerance. Nat Rev Immunol 2008; 8: 362-371.

26. Rouzaut A, Garasa S, Teijeira A, Gonzalez I, Martinez-Forero I, SuARez N et al. Dendritic cells adhere to and transmigrate across lymphatic endothelium in response to IFN-alpha. Eur J Immunol 2010; 40: 3054-3063.

27. Teijeira A, Palazon A, Garasa S, Marre D, Auba C, Rogel A et al. CD137 on inflamed lymphatic endothelial cells enhances CCL21-guided migration of dendritic cells. FASEB J 2012; 26 : 3380-3392.

28. GoRdon S. Pattern recognition receptors: doubling up for the innate immune response. Cell 2002; 111: 927-930.

29. Matzinger P. An innate sense of danger. Semin Immunol 1998; 10: 399-415.

30. Matzinger P. Tolerance, danger, and the extended family. Annu Rev Immunol 1994; 12: 9911045.

31. Reid SD, Penna G, Adorini L. The control of T cell responses by dendritic cell subsets. Curr Opin Immunol 2000; 12: 114-121.

32. Zou J, KaWai T, Tsuchida T, Kozaki T, Tanaka H, SHIN KS et al. Poly IC triggers a cathepsin Dand IPS-1-dependent pathway to enhance cytokine production and mediate dendritic cell necroptosis. Immunity 2013; 38: 717-728. 
33. JANEwAY CA, JR., Medzhitov R. Innate immune recognition. Annu Rev Immunol 2002; 20: 197-216.

34. Sporri R, Reis e Sousa C. Inflammatory mediators are insufficient for full dendritic cell activation and promote expansion of CD4+ T cell populations lacking helper function. Nat Immunol 2005; 6: 163-170.

35. Sallusto F, Lanzavecchia A. The instructive role of dendritic cells on T-cell responses. Arthritis Res 2002; 4 Suppl 3: S127-132.

36. Romani N, Gruner S, Brang D, Kampgen E, Lenz A, Trockenbacher B et al. Proliferating dendritic cell progenitors in human blood. J Exp Med 1994; 180: 83-93.

37. Inaba K, Inaba M, Romani N, Aya H, Deguchi M, IKEHARA $S$ et al. Generation of large numbers of dendritic cells from mouse bone marrow cultures supplemented with granulocyte/ macrophage colony-stimulating factor. J Exp Med 1992; 176: 1693-1702.

38. Mazzolini G, Alfaro C, Sangro B, Feijoo E, Ruiz $\mathrm{J}$, BENITO A et al. Intratumoral injection of dendritic cells engineered to secrete interleukin-12 by recombinant adenovirus in patients with metastatic gastrointestinal carcinomas. J Clin Oncol 2005; 23: 999-1010.

39. Santini SM, Di Pucchio T, Lapenta C, Parlato S, Logozzi M, Belardelli F. A new type I IFN-mediated pathway for the rapid differentiation of monocytes into highly active dendritic cells. Stem Cells 2003; 21: 357-362.

40. Mohamadzadeh M, Berard F, Essert G, Chalouni C, Pulendran B, Davoust J et al. Interleukin 15 skews monocyte differentiation into dendritic cells with features of Langerhans cells. J Exp Med 2001; 194: 1013-1020.

41. Steinman RM, Nussenzweig MC. Avoiding horror autotoxicus: the importance of dendritic cells in peripheral T cell tolerance. Proc Natl Acad Sci U S A 2002; 99: 351-358.

42. Ito T, Amakawa R, Inaba M, Hori T, Ota M, NaKaMURA $\mathrm{K}$ et al. Plasmacytoid dendritic cells regulate Th cell responses through OX40 ligand and type I IFNs. J Immunol 2004; 172: 4253-4259.

43. Blom B, Ho S, Antonenko S, Liu YJ. Generation of interferon alpha-producing predendritic cell (Pre-DC)2 from human CD34(+) hematopoietic stem cells. J Exp Med 2000; 192: 17851796.

44. Donaghy H, Gazzard B, Gotch F, Patterson S. Dysfunction and infection of freshly isolated blood myeloid and plasmacytoid dendritic cells in patients infected with HIV-1. Blood 2003; 101: 4505-4511.
45. Colonna M, Trinchieri G, Liu YJ. Plasmacytoid dendritic cells in immunity. Nat Immunol 2004; 5: 1219-1226.

46. LIU YJ. IPC: professional type 1 interferonproducing cells and plasmacytoid dendritic cell precursors. Annu Rev Immunol 2005; 23 : 275-306.

47. Reizis B, Bunin A, Ghosh HS, Lewis KL, SisiraK V. Plasmacytoid dendritic cells: recent progress and open questions. Annu Rev Immunol 2011; 29: 163-183.

48. Tel J, Schreibelt G, Sittig SP, Mathan TS, BusCHOw SI, CRuz LJ et al. Human plasmacytoid dendritic cells efficiently cross-present exogenous Ags to CD8+ T cells despite lower Ag uptake than myeloid dendritic cell subsets. Blood 2013; 121: 459-467.

49. Tel J, Aarntzen EH, Baba T, Schreibelt G, Schulte BM, BEnitez-Ribas D et al. Natural human plasmacytoid dendritic cells induce antigen-specific T-cell responses in melanoma patients. Cancer Res 2013; 73: 1063-1075.

50. Joffre OP, Segura E, Savina A, Amigorena S. Cross-presentation by dendritic cells. Nat Rev Immunol 2012; 12: 557-569.

51. Segura E, Villadangos JA. A modular and combinatorial view of the antigen cross-presentation pathway in dendritic cells. Traffic 2011; 12: 1677-1685.

52. Mantegazza AR, Magalhaes JG, Amigorena S, MARKS MS. Presentation of phagocytosed antigens by MHC class I and II. Traffic 2013; 14 : 135-152.

53. Hegde RS, Ploegh HL. Quality and quantity control at the endoplasmic reticulum. Curr Opin Cell Biol 2010; 22: 437-446.

54. Schulze MS, Wucherpfennig KW. The mechanism of HLA-DM induced peptide exchange in the MHC class II antigen presentation pathway. Curr Opin Immunol 2012; 24: 105-111.

55. BEvAN MJ. Cross-priming for a secondary cytotoxic response to minor $\mathrm{H}$ antigens with $\mathrm{H}-2$ congenic cells which do not cross-react in the cytotoxic assay. J Exp Med 1976; 143: 1283-1288.

56. Bevan MJ. Minor $\mathrm{H}$ antigens introduced on $\mathrm{H}-2$ different stimulating cells cross-react at the cytotoxic $\mathrm{T}$ cell level during in vivo priming. J Immunol 1976; 117: 2233-2238.

57. Dresch C, Leverrier Y, Marvel J, Shortman K. Development of antigen cross-presentation capacity in dendritic cells. Trends Immunol 2012; 33: 381-388.

58. Restifo NP, Dudley ME, Rosenberg SA. Adoptive immunotherapy for cancer: harnessing the $\mathrm{T}$ cell response. Nat Rev Immunol 2012; 12 : 269-281. 
59. Cebrian I, Visentin G, Blanchard N, Jouve M, BoBARD A, MoITA C et al. Sec22b regulates phagosomal maturation and antigen crosspresentation by dendritic cells. Cell 2011; 147: 1355-1368.

60. Lin ML, Zhan Y, Proietto AI, Prato S, Wu L, HEATH WR et al. Selective suicide of cross-presenting CD8+ dendritic cells by cytochrome c injection shows functional heterogeneity within this subset. Proc Natl Acad Sci U S A 2008; 105: 3029-3034.

61. Dani A, Chaudhry A, Mukherjee P, Rajagopal D, Bhatia S, George A et al. The pathway for MHCII-mediated presentation of endogenous proteins involves peptide transport to the endo-lysosomal compartment. J Cell Sci 2004; 117: 4219-4230.

62. McDonnell AM, Robinson BW, Currie AJ. Tumor antigen cross-presentation and the dendritic cell: where it all begins? Clin Dev Immunol 2010; 2010: 539519.

63. Melero I, Bach N, Chen L. Costimulation, tolerance and ignorance of cytolytic T LYMPHOCYTES in immune responses to tumor antigens. Life Sci 1997; 60: 2035-2041.

64. Kanzler H, Barrat FJ, Hessel EM, Coffman RL. Therapeutic targeting of innate immunity with Toll-like receptor agonists and antagonists. Nat Med 2007; 13: 552-559.

65. Palm NW, Medzhitov R. Pattern recognition receptors and control of adaptive immunity. Immunol Rev 2009; 227: 221-233.

66. Coffman RL, Sher A, Seder RA. Vaccine adjuvants: putting innate immunity to work. Immunity 2010; 33: 492-503.

67. Medzhitov R, Janeway CA Jr. Innate immunity: the virtues of a nonclonal system of recognition. Cell 1997; 91: 295-298.

68. KAWAI T, AKIRA S. Toll-like receptor and RIGI-like receptor signaling. Ann N Y Acad Sci 2008; 1143: 1-20.

69. Barral PM, Sarkar D, Su ZZ, Barber GN, DeSalle R, RACANIELlo VR et al. Functions of the cytoplasmic RNA sensors RIG-I and MDA-5: key regulators of innate immunity. Pharmacol Ther 2009; 124: 219-234.

70. NAKhaE P, Genin P, Civas A, Hiscott J. RIG-I-like receptors: sensing and responding to RNA virus infection. Semin Immunol 2009; 21: 215222.

71. Nicodemus CF, BereK JS. TLR3 agonists as immunotherapeutic agents. Immunotherapy 2010; 2: 137-140.

72. Heath WR, Carbone FR. Dendritic cell subsets in primary and secondary $\mathrm{T}$ cell responses at body surfaces. Nat Immunol 2009; 10: 1237-1244.
73. Merad M, Manz MG. Dendritic cell homeostasis. Blood 2009; 113: 3418-3427.

74. Villadangos JA, Schnorrer P. Intrinsic and cooperative antigen-presenting functions of dendritic-cell subsets in vivo. Nat Rev Immunol 2007; 7: 543-555.

75. Shortman K, Heath WR. The CD8+ dendritic cell subset. Immunol Rev 2010; 234: 18-31.

76. Dudziak D, Kamphorst AO, HeidKamp GF, BuchHolz VR, TRUMPFHELLER C, YAMAZAKI S et al. Differential antigen processing by dendritic cell subsets in vivo. Science 2007; 315: 107-111.

77. Iyoda T, Shimoyama S, Liu K, Omatsu Y, AKiyama Y, MaEda Y et al. The CD8+ dendritic cell subset selectively endocytoses dying cells in culture and in vivo. J Exp Med 2002; 195: 12891302.

78. Schnorrer P, Behrens GM, Wilson NS, Pooley JL, SMITH CM, EL-SuKKari D et al. The dominant role of $\mathrm{CD} 8+$ dendritic cells in cross-presentation is not dictated by antigen capture. Proc Natl Acad Sci U S A 2006; 103: 1072910734.

79. Wilson NS, El-Sukkari D, Belz GT, Smith CM, Steptoe RJ, Heath WR et al. Most lymphoid organ dendritic cell types are phenotypically and functionally immature. Blood 2003; 102 : 2187-2194.

80. Hong L, Webb TJ, WiLkes DS. Dendritic cell-T cell interactions: CD8 alpha alpha expressed on dendritic cells regulates $\mathrm{T}$ cell proliferation. Immunol Lett 2007; 108: 174-178.

81. Bedou S, Whitney PG, Waithman J, Eidsmo L, WaKIM L, CAMINSCHI I et al. Cross-presentation of viral and self antigens by skin-derived CD103+ dendritic cells. Nat Immunol 2009; 10: 488-495.

82. Hildner K, Edelson BT, Purtha WE, Diamond M, Matsushita H, Kohyama M et al. Batf3 deficiency reveals a critical role for CD8alpha+ dendritic cells in cytotoxic T cell immunity. Science 2008; 322: 1097-1100.

83. Edelson BT, Kc W, Juang R, Kohyama M, Benoit LA, KLEKotKa PA et al. Peripheral CD103+ dendritic cells form a unified subset developmentally related to CD8alpha+ conventional dendritic cells. J Exp Med 2010; 207: 823-836.

84. Schiavoni G, Mattei F, Sestili P, Borghi P, Venditti M, Morse HC, 3RD et al. ICSBP is essential for the development of mouse type I interferonproducing cells and for the generation and activation of CD8alpha(+) dendritic cells. J Exp Med 2002; 196: 1415-1425.

85. Tailor P, Tamura T, Morse HC, 3rd, Ozato K. The BXH2 mutation in IRF8 differentially impairs dendritic cell subset development in the mouse. Blood 2008; 111: 1942-1945. 
86. Arina A, Tirapu I, Alfaro C, Rodriguez-Calvillo M, Mazzolini G, Inoges S et al. Clinical implications of antigen transfer mechanisms from malignant to dendritic cells. exploiting crosspriming. Exp Hematol 2002; 30: 1355-1364.

87. Melero I, Arina A, Murillo O, Dubrot J, Alfaro C, Perez-Gracia JL et al. Immunogenic cell death and cross-priming are reaching the clinical immunotherapy arena. Clin Cancer Res 2006; 12: 2385-2689.

88. Idoyaga J, Lubkin A, Fiorese C, Lahoud MH, CamINSCHI I, HuANG Y et al. Comparable T helper 1 (Th1) and CD8 T-cell immunity by targeting HIV gag p24 to CD8 dendritic cells within antibodies to Langerin, DEC205, and Clec9A. Proc Natl Acad Sci US A 2011; 108: 2384-2389.

89. Sancho D, Mourao-Sa D, Joffre OP, Schulz O, Rogers NC, Pennington DJ et al. Tumor therapy in mice via antigen targeting to a novel, DCrestricted C-type lectin. J Clin Invest 2008; 118: 2098-2110.

90. Miller G, Pillarisetty VG, Shah AB, Lahrs S, DeMatteo RP. Murine Flt3 ligand expands distinct dendritic cells with both tolerogenic and immunogenic properties. J Immunol 2003; 170: 3554-3564.

91. Naik SH, Proietto AI, Wilson NS, Dakic A, SchNORRER P, FuChSBERGER M et al. Cutting edge: generation of splenic CD8+ and CD8- dendritic cell equivalents in Fms-like tyrosine kinase 3 ligand bone marrow cultures. J Immunol 2005; 174: 6592-6597.

92. Sathe P, Pooley J, Vremec D, Mintern J, Jin JO, Wu $L$ et al. The acquisition of antigen crosspresentation function by newly formed dendritic cells. J Immunol 2011; 186: 5184-5192.

93. De Brito C, Tomkowiak M, Ghittoni R, Caux C, LEVERRIER Y, MARVEL J. CPG promotes cross-presentation of dead cell-associated antigens by pre-CD8alpha+ dendritic cells. J Immunol 2011; 186: 1503-1511.

94. Kurts C, Robinson BW, Knolle PA. Cross-priming in health and disease. Nat Rev Immunol 2010; 10: 403-414.

95. Pooley JL, Heath WR, Shortman K. Cutting edge: intravenous soluble antigen is presented to CD4 T cells by CD8- dendritic cells, but cross-presented to CD8 T cells by CD8+ dendritic cells. J Immunol 2001; 166: 5327-5330.

96. den HaAn JM, Bevan MJ. Constitutive versus activation-dependent cross-presentation of immune complexes by $\mathrm{CD} 8(+)$ and $\mathrm{CD} 8(-)$ dendritic cells in vivo. J Exp Med 2002; 196: 817-827.

97. Moron G, Rueda P, Casal I, Leclerc C. CD8alpha$\mathrm{CD} 11 \mathrm{~b}+$ dendritic cells present exogenous virus-like particles to CD8+ T cells and sub- sequently express CD8alpha and CD205 molecules. J Exp Med 2002; 195: 1233-1245.

98. Ruedl C, Storni T, Lechner F, Bachi T, Bachmann MF. Cross-presentation of virus-like particles by skin-derived CD8(-) dendritic cells: a dispensable role for TAP. Eur J Immunol 2002; 32: 818-825.

99. BACKER R, van Leeuwen F, Kraal G, den Haan JM. CD8- dendritic cells preferentially crosspresent Saccharomyces cerevisiae antigens. Eur J Immunol 2008; 38: 370-380.

100. Alfaro C, Pérez-Gracia JL, Suarez N, Rodríguez J, Fernández de Sanmamed M, Sangro B et al. Pilot clinical trial of type 1 dendritic cells loaded with autologous tumor lysates combined with GM-CSF, pegylated IFN, and cyclophosphamide for metastatic cancer patients. J Immunol 2011; 187: 6130-6142.

101. Yamazaki C, SugiYama M, Оhта T, Нemmi H, HamadA E, SASAKI I et al. Critical Roles of a Dendritic Cell Subset Expressing a Chemokine Receptor, XCR1. J Immunol 2013; 190: 60716082.

102. Poulin LF, Salio M, Griessinger E, Anjos-Afonso F, CRACIUN L, CHEN JL, et al. Characterization of human DNGR-1+ BDCA3+ leukocytes as putative equivalents of mouse CD8alpha+ dendritic cells. J Exp Med 2010; 207: 1261-1271.

103. Dzionek A, Fuchs A, Schmidt P, Cremer S, Zysk M, MiLtenyi S et al. BDCA-2, BDCA-3, and BDCA-4: three markers for distinct subsets of dendritic cells in human peripheral blood. J Immunol 2000; 165: 6037-6046.

104. Bachem A, Guttler S, Hartung E, Ebstein F, Schaefer M, TAnnert A et al. Superior antigen cross-presentation and XCR1 expression define human CD11c+CD141+ cells as homologues of mouse CD8+ dendritic cells. J Exp Med 2010; 207: 1273-1281.

105. Contreras V, Urien C, Guiton R, Alexandre Y, Vu Manh TP, AndRIEU T et al. Existence of CD8alpha-like dendritic cells with a conserved functional specialization and a common molecular signature in distant mammalian species. J Immunol 2010; 185: 3313-3325.

106. Crozat K, Guiton R, Contreras V, Feulllet V, DuTERTRE CA, VEnTRE E et al. The XC chemokine receptor 1 is a conserved selective marker of mammalian cells homologous to mouse CD8alpha+ dendritic cells. J Exp Med 2010; 207: 1283-1292.

107. Jongbloed SL, Kassianos AJ, McDonald KJ, Clark GJ, Ju X, Angel CE et al. Human CD141+ (BDCA-3)+ dendritic cells (DCs) represent a unique myeloid DC subset that cross-presents necrotic cell antigens. J Exp Med 2010; 207: 1247-1260. 
108. Caminschi I, Proietto AI, Ahmet F, Kitsoulis S, SHIN TEH J, Lo JC, et al. The dendritic cell subtype-restricted C-type lectin Clec9A is a target for vaccine enhancement. Blood 2008; 112: 3264-3273.

109. Dorner BG, Dorner MB, Zhou X, Opitz C, Mora A, GutTler $S$ et al. Selective expression of the chemokine receptor XCR1 on cross-presenting dendritic cells determines cooperation with CD8+ T cells. Immunity 2009; 31: 823833.

110. DALOD M. Professional cross-presenting CD8alpha-type CD141(hi) dendritic cells: we have got you in our skin! Immunity 2012; 37 : 3-5.

111. Mittag D, Proietto AI, Loudovaris T, Mannering SI, VRemec D, Shortman K et al. Human dendritic cell subsets from spleen and blood are similar in phenotype and function but modified by donor health status. J Immunol 2011; 186: 6207-6217.

112. Haniffa M, Shin A, Bigley V, McGovern N, Teo P, SEE $P$ et al. Human tissues contain CD141hi cross-presenting dendritic cells with functional homology to mouse CD103+ nonlymphoid dendritic cells. Immunity 2012; 37: 6073.

113. Segura E, Durand M, Amigorena S. Similar antigen cross-presentation capacity and phagocytic functions in all freshly isolated human lymphoid organ-resident dendritic cells. J Exp Med 2013; 210: 1035-1047.

114. Cohn L, Chatterjee B, Esselborn F, Smed-Sorensen A, Nakamura N, Chalouni $\mathrm{C}$ et al. Antigen delivery to early endosomes eliminates the superiority of human blood BDCA3+ dendritic cells at cross presentation. J Exp Med 2013; 210: 1049-1063.

115. Sancho D, Joffre OP, Keller AM, Rogers NC, Martinez D, Hernanz-Falcon $\mathrm{P}$ et al. Identification of a dendritic cell receptor that couples sensing of necrosis to immunity. Nature 2009; 458: 899-903.

116. Iborra S, Izquierdo HM, Martinez-Lopez M, Blanco-Menendez N, Reis e Sousa C, Sancho D. The DC receptor DNGR-1 mediates cross-priming of CTLs during vaccinia virus infection in mice. J Clin Invest 2012; 122:1628-1643.

117. Zelenay S, Keller AM, Whitney PG, Schraml BU, Deddouche S, Rogers NC et al. The dendritic cell receptor DNGR-1 controls endocytic handling of necrotic cell antigens to favor cross-priming of CTLs in virus-infected mice. J Clin Invest 2012; 122: 1615-1627.

118. SANChO D, ReIS E Sousa C. Signaling by myeloid C-type lectin receptors in immunity and homeostasis. Annu Rev Immunol 2012; 30: 491529.

119. Jiang W, Swiggard WJ, Heufler C, Peng M, Mirza A, Steinman RM et al. The receptor DEC-205 expressed by dendritic cells and thymic epithelial cells is involved in antigen processing. Nature 1995; 375: 151-155.

120. Hawiger D, Inaba K, Dorsett Y, Guo M, MahnKe K, RIVERA M et al. Dendritic cells induce peripheral T cell unresponsiveness under steady state conditions in vivo. J Exp Med 2001; 194 : 769-779.

121. Geijtenbeek TB, Torensma R, van Vliet SJ, van Duijnhoven GC, Adema GJ, van Kooyk Y et al. Identification of DC-SIGN, a novel dendritic cell-specific ICAM-3 receptor that supports primary immune responses. Cell 2000; 100: 575-585.

122. van den Berg LM, Gringhuis SI, GeiJtenbeek TB. An evolutionary perspective on C-type lectins in infection and immunity. Ann N Y Acad Sci 2012; 1253: 149-158.

123. Palucka K, Banchereau J, Mellman I. Designing vaccines based on biology of human dendritic cell subsets. Immunity 2010; 33: 464-478.

124. Galluzzi L, Senovilla L, Vaccheldi E, Eggermont A, Fridman WH, GaLON J et al. Trial watch: Dendritic cell-based interventions for cancer therapy. Oncoimmunology 2012; 1: 11111134.

125. FInN OJ. Cancer immunology. N Engl J Med 2008; 358: 2704-2715.

126. Melief CJ. Cancer immunotherapy by dendritic cells. Immunity 2008; 29: 372-383.

127. Delamarre L, Mellman I. Harnessing dendritic cells for immunotherapy. Semin Immunol 2011; 23: 2-11.

128. Melero I, Vile RG, Colombo MP. Feeding dendritic cells with tumor antigens: self-service buffet or a la carte? Gene Ther 2000; 7: 11671170 .

129. Le Bon A, Etchart N, Rossmann C, Ashton M, Hou S, Gewert D et al. Cross-priming of CD8+ T cells stimulated by virus-induced type I interferon. Nat Immunol 2003; 4: 1009-1015. 
